\title{
Management Dilemmas in Borderline Ovarian Tumor
}

\author{
Arpana Haritwal ${ }^{1}$, Bela Makhija ${ }^{1}$, Manjeet Arora ${ }^{1}$, Dipti Agrawal ${ }^{1}$, Prashant Goyal $^{2}$
}

\begin{abstract}
Objective: Borderline ovarian tumors (BOT) constitute 15\% of all epithelial ovarian cancers. The aim of this study is to analyze and discuss the management dilemmas associated with BOT. The purpose of this article was to collect and review the data on management dilemmas of BOT from numerous articles published since 1995. Additionally, the data of four patients with BOT, who were treated in our Institute, are presented and analyzed.

Materials and Methods: For literature review we performed a literature search of relevant articles that were based on management dilemmas. Additionally, the data of 4 patients with BOT, who were treated in our Institute, are reported and reviewed by medical data information and patient interview, to establishing a database for a better understanding of the management dilemmas of BOT. Results: All the four cases were of reproductive age group. In three cases conservative fertility sparing surgery was done and in one patient radical surgery was done. All the four cases did not require adjuvant therapy. BOTs did not affect the outcome of pregnancy. Follow up of all the four cases is uneventful with no evidence of recurrence.

Conclusion: Surgical management to excise all visible tumor tissue remains the keystone of therapy. Fertility being an important issue; conservative laparoscopic surgery is also a viable treatment option. Progression free survival is not influenced by the type of surgical approach (laparoscopic v/s laparotomy). Overall survival does not depend on the type of surgery (fertility sparing v/s nonsparing surgery). Even in advanced disease there is no proven benefit of adjuvant chemotherapy or radiotherapy.

Keywords: Borderline Ovarian Tumor, CA-125, Invasive Ovarian Carcinoma, Pregnancy
\end{abstract}

\section{Introduction}

Borderline ovarian tumors (BOT) constitute $15 \%$ of all epithelial ovarian cancers. As the term borderline implies they clinically behave intermediate between benign and malignant tumors. Synonyms of BOT include tumors of borderline malignancy, tumors of low malignant potential, and atypical proliferative tumors (1). Histologically, the borderline tumors are defined by the presence of nuclear atypia, epithelial stratification, mitotic activity, and absence of stromal invasion $(2,3)$. Lack of invasion of the ovarian stroma by neoplastic cells is the cardinal feature that separates BOT from invasive ovarian carcinomas (IOC). According to the World Health Organization classification schemata, 2003 (4), BOT are classified on the basis of histopathology and histogenesis into serous, mucinous, endometrioid, clear cell, and transitional (Brenner) subtypes. Serous and mucinous neoplasms constitute the majority of BOT and occur mostly in women of reproductive age. The mean age of presentation of BOT is approximately 20 years earlier than that of IOC (5). It is most frequently seen between the ages 30 and 50 years. Because BOT behaves in a much less aggressive way, in most women the condition has not spread beyond the ovary when it is diagnosed (stage 1 disease). Despite some of the histologic features suggestive of malignancy, the clinical prognosis of these tumors is excellent compared with that of invasive ovarian carcinoma. Although patients have an excellent prognosis, risk of recurrence remains in some cases (6). We present an interesting case series of BOTs and discuss the management dilemmas associated.

\section{Materials and Methods}

For literature review we performed a literature search of relevant articles that were based on management dilemmas. We searched Medline/Pubmed electronic database and "Google Scholar" search engine in the internet for articles on this topic since 1995. Additionally, the data of 4 patients with BOT, who were treated in our Institute, are reported and reviewed by medical data information and patient interview, to establishing a database for a better understanding of the management dilemmas of BOT.

\section{Case 1}

A 19-years-old unmarried girl presented at our hospital with the complaint of lower abdominal pain for 6 years. Menstrual cycles were irregular with excessive bleeding and pain during cycles since $4-5$ years. Ultrasound (USG) examination showed right ovarian cyst measuring $10 \times 10$ $\mathrm{cm}$ with multiple septations and no solid area, suggestive

Received 27 January 2014, Accepted 1 April 2014, Revised 24 March 2014, Available online 14 April 2014 
of mucinous cyst. Serum tumor marker CA-125 and CA-19.9 were within normal limit $(31.1 \mathrm{U} / \mathrm{ml}$ and 7.0 $\mathrm{U} / \mathrm{ml}$ respectively). Patient was admitted and we did her laparotomy followed by right ovarian cystectomy. There was no per operative evidence of malignancy. Frozen section revealed diagnosis of benign mucinous cystadenoma. This patient again presented 11 months post operatively with an abdominal mass and pain. Per abdominally a firm mass of $22 \times 20 \mathrm{~cm}$ size, regular smooth and freely mobile was palpable. This time CA125 was high $(96.5 \mathrm{U} / \mathrm{ml})$ and CA19.9 was within normal limit $(25 \mathrm{U} / \mathrm{ml})$. USG showed mucinous cyst of $18 \times 20$ $\mathrm{cm}$ size in right ovary.

In this patient, our considerations prior to planning surgery were young age, quick recurrence of the tumor and high CA-125 levels. Staging laparotomy was done. Per operatively there was a twisted, smooth, mobile right ovarian cyst of $22 \times 20 \mathrm{~cm}$ with multiple septations, same removed and sent for frozen section. Left ovary was normal. Frozen section examination revealed diagnosis of mucinous cystadenoma of right ovary (intestinal type) with borderline malignant potential. It was stage I A mucinous BOT (confirmed with histopathology report). Patient was willing for regular follow up and hence, opted for fertility sparing surgery. No adjuvant therapy was given. She is in regular follow up with us for 6 years with no evidence of disease. She married at the age of 22 years and had one full term vaginal delivery.

\section{Case 2}

A 25-years-old, gravida 2, para 2, with 25 weeks gestation presented with a large multiloculated cystic mass in pelvis. Serum CA-125 was slightly high $(75 \mathrm{U} / \mathrm{ml})$, and CA-19.9 was within normal limit $(20 \mathrm{U} / \mathrm{ml})$. Relatives opted to continue the pregnancy; hence only right salpingo-oophorectomy was done. Per operative findings showed gravid uterus of 26 weeks, and $12 \times 10 \mathrm{~cm}$ smooth right ovarian cyst with multiple septae and solid areas along with 2 liters sero-sanguineous fluid, and grossly normal left ovary. Histopathology examination revealed mucinous BOT stage I. She reached uneventfully till term. Elective LSCS with bilateral tubal ligation was done in view of previous LSCS (due to contracted pelvis). During LSCS, second look was done. There was no evidence of macroscopic disease, right ovary was absent, left tube and ovary was normal. Patient is in regular follow up with us, with regular CA-125 levels and USG for past 12 years with no sign of recurrence.

\section{Case 3}

A 17-years-old unmarried girl presented with diffuse pain abdomen for 2 months. On per-abdominal examination, there was a mobile, tender, and firm mass of 14-16 weeks of gestational size in suprapubic region. USG examination showed a hyper-echoic solid left tubo-ovarian mass of $10.4 \times 7.7 \mathrm{~cm}$ size with normal uterus along with mild ascites. Serum CA-125 was markedly raised (2473 U/ $\mathrm{ml})$. In CECT scan, there was a large heterogenously enhancing mass of $10 \times 7 \times 6 \mathrm{~cm}$ in supravesical region likely arising from left adenexa, right ovary was bulky with multiple cysts, free fluid present in pelvic cavity, and multiple enlarged mesentric lymph nodes. Staging laparotomy was done. Per operatively there was left ovarian cyst of $10 \times 6 \mathrm{~cm}$ size with irregular surface excrescences and solid areas, the same were removed and sent for frozen section analysis. Right ovary had small irregular growths. Peritoneal deposits, omental deposits and an omental lymph node were identified, resected and sent for histopathologic examination. Frozen section was suggestive of serous BOT stage III.

We were in dilemma whether to go in for conservative management in view of adolescent age and borderline malignancy or to do radical surgery keeping in view her very high CA-125 levels, clinically advanced stage (stage III) BOT, poor socioeconomic status and poor compliance for follow-up. Since relatives were not willing for relook surgery and were not ready to accept the higher risk of recurrence after conservative surgery, radical surgery was done. Post operative period was uneventful. Histopathological report revealed final diagnosis of serous BOT with non invasive implants. On postoperative day $10, \mathrm{CA}-125$ came down to within normal range (33.31 U/ $\mathrm{ml}$ ) and patient is in regular follow up for past 5 years.

\section{Case 4}

A 30-years-old, G3P1L1A1 came to hospital at 34 weeks gestation for antenatal check-up. Her past history revealed that she had one missed abortion 6 years back. A huge left ovarian cyst of $20 \times 15 \mathrm{~cm}$ with papillary projections from cyst wall, was also diagnosed at the same time. At that time her serum CA-125 was within normal range $(20 \mathrm{U} / \mathrm{ml})$. Suction and evacuation was done for missed abortion. In the same sitting, patient was taken up for staging laparotomy. Left salpingo-oophorectomy was done and cyst sent for frozen section which revealed the diagnosis of mucinous BOT stage IA. Hence, no further surgery was done. Her post-operative period was uneventful. After this, she had one full term normal vaginal delivery. In present pregnancy, she had also good obstetric and perinatal outcome. She is in regular follow-up with us for 8 years.

\section{Results and Discussion}

Surgical removal is the cornerstone in the management of BOTs, but the surgical approach and the extent of the staging procedure are currently debated (7). According to the clinical practical guidelines worldwide, a complete comprehensive staging is advised when fertility preservation is not a concern. Complete comprehensive staging includes; Hysterectomy with bilateral salpingo-oophorectomy with lymphadenectomy, infracolicomentectomy and omental biopsy.

\section{Conservative/ fertility sparing surgery}

When is conservative surgery appropriate? Indications:

1) Fertility preservation is a concern,

2) Stage 1 disease, 
3) BOTs with non-invasive implants.

The mean age when BOT present is in the childbearing period and a fertility-sparing approach is an important issue. Conservative or fertility sparing surgery includes unilateral salpingo-oophorectomy, infracolicomentectomy and multiple peritoneal biopsies. Systematic biopsies of macroscopically normal contralateral ovary is not recommended as they do not exclude recurrent disease, and may interfere with fertility as a result of adhesions (7-9). In another recent review, Cadron et al. (7) only recommended performing cystectomy when there is a bilateral tumor or when there is a previous history of unilateral adnexectomy (Figure 1). In the literature, relapse rates are between 0 and 20\% after adnexectomy, between 12 and 58\% after cystectomy, and between 3 and $6 \%$ after radical surgery $(7,10,11)$. There is no significant difference in recurrence free survival or overall survival between fertility sparing surgery and radical surgery (10). In a recent review on the conservative surgery of BOT, Tinelli et al. (12) concluded that unilateral salpingooophorectomy must be considered as the first choice of conservative treatment, which can be performed by laparoscopy. Women selecting conservative approach should be cautioned about the risk of recurrence and need for future surgery. Should we remove the remaining ovary and uterus once the family is complete? As histology of recurrence is mostly borderline and given a recurrence rate of $0-20 \%$, one could recommend waiting until recurrence develops to perform radical surgery (10). However few patients may choose to have definitive treatment as soon as their family is complete because of psychological stress. In our case series, fertility preservation was a concern in all the 4 cases but we were able to do conservative surgery in only 3 cases as one case had advanced stage disease with higher pre-operative CA-125 levels and poor compliance for follow-up.

\section{Laparoscopy v/s laparotomy}

In the last two decades, laparoscopy has become a good alternative to laparotomy. Laparoscopic surgery has greatly changed the approach to ovarian masses and laparoscopic management is considered to be safe and adequate even in early IOC $(13,14)$. Fauvet et al. (15) calculated the recurrence rates according to initial surgical approach which were $12.1 \%$ in Laparoscopy, $11.9 \%$ in laparoconversion and $9.1 \%$ in laparotomy. Romagnolo et al. (16) reported the overall incidence of relapse of $11.5 \%$ in patients who underwent laparoscopy (not statistically different from laparotomy). Donnez et al. (17) and Beiner et al. (18) also reported similar incidences. A retrospective study conducted at Taiwan from 1984 to 2008 also showed that 5-year overall survival and recurrence free survival remains the same by both the approaches (10). However points of concern with laparoscopy are; 1) Chance of

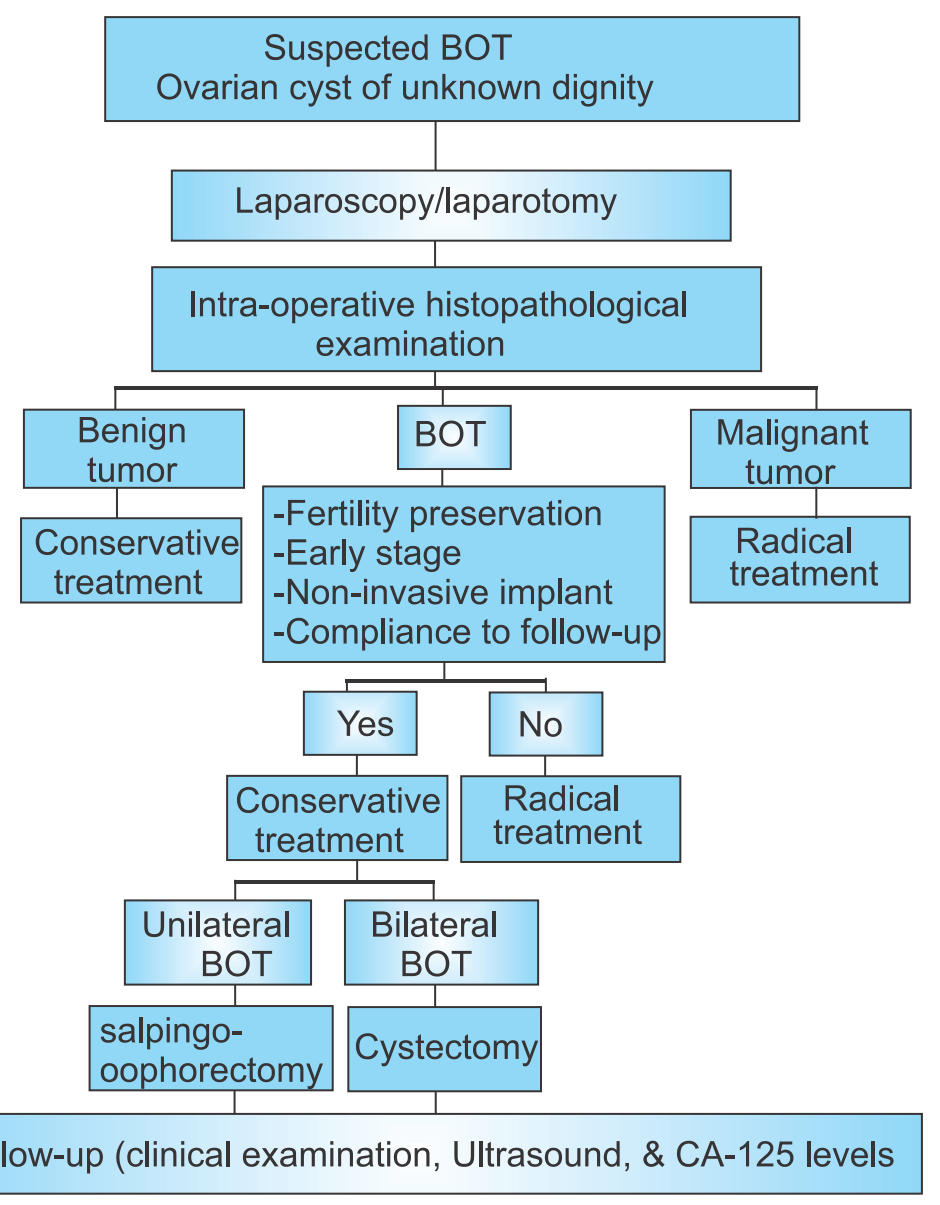

Figure 1. Algorithm for management of suspected Borderline ovarian tumor (BOT). 
cyst rupture is much higher, 2) Development of port site metastases, and 3) Increased chances of unstaging or inappropriate staging.

Recommendation is that, the laparoscopic treatment in BOT should be reserved to masses not more than 5 $\mathrm{cm}(7,19)$. When conservative therapy is desired, entire affected ovary should be removed. Considering the good prognosis, low incidence of relapse and high progression free survival, conservative laparoscopic surgery is an attractive option for young women who wish to preserve childbearing, provided operating laparoscopic surgeon is adequately skilled. In our case series, all patients had ovarian cyst measuring more than $5 \mathrm{~cm}$, hence we opted for laparotomy.

\section{Progression to invasive ovarian carcinoma (IOC)}

There are 13 studies in the literature showing 91 patients of BOT who experienced recurrence as $\operatorname{IOC}(8,16,19-29)$. The invasive recurrence rates vary between 8 and $73 \%$ (7). Morice et al. (30) evaluated 80 patients with advanced serous BOTs and concluded that the only prognostic factor for progression to IOC was the type of peritoneal implants. The chance of developing invasive disease over a period of 5-years in patients with advanced serous BOTs was $31 \%$ for invasive implants and $2 \%$ for non-invasive implants $(\mathrm{p}<0.002)(30)$. The incidence is higher in studies including patients with advanced disease stages and invasive peritoneal implants. The strongest prognostic factor in patients with an advanced-stage BOT is the use of conservative surgery (31). In our case series, 3 patients had no peritoneal implants and one had advanced disease but non-invasive implants. Our all 4 patients had follow-up of more than 5 years but none of them progressed to IOC.

\section{Need for lymphadenectomy}

Lymphadenectomy can be omitted for confirmed BOTs even for the advanced disease as there is no difference in recurrence or survival rate (9). Lymph node involvement does not adversely impact the overall survival of patients with serous BOT, but there is controversy as to whether this finding is associated with a decrease in recurrence-free survival. It is prudent to exercise lymph node sampling in apparently stage I \& II disease if there is any doubt as to the nature of ovarian tumor or in the absence of frozen section facilities $(9,20)$. In our case series, lymphadenectomy was done only in one patient who had advanced stage BOT.

\section{Restaging procedures}

Retrospective studies show that, even when such staging procedures are performed, they have no impact on the survival $(9,32)$. In patients in whom surgery has been performed for presumed benign disease and there is no description of the abdominal cavity and peritoneal surface, we do recommend restaging because in $39 \%$ of BOTs, the omentum is involved, with $9 \%$ invasive implants (33).

\section{Role of adjuvant therapy}

There is no proven benefit from adjuvant chemotherapy or radiotherapy even in advanced stage disease with the presence of invasive implants (30). Four prospective randomized trials conducted in Norway showed that, for stage I and II disease, the addition of adjuvant therapy did not improve survival, but on the contrary toxicity was added, with overall survival rates of $99 \%$ and $94 \%$ for no adjuvant therapy and adjuvant therapy, respectively. Long term follow up of these patients is required, as recurrences as late as 39 years after initial therapy have been reported (33-35). Follow up should be every 3 months during the first 2 years, every 6 months for the third through fifth years, and yearly thereafter. Patients should be evaluated with clinical examination, vaginal ultrasound, and CA125 measurements (36). In our case series, only one patient had advanced BOT with implants, but they were non-invasive. Hence, no adjuvant therapy was required.

\section{Treatments of recurrent disease}

Predictors of recurrence in BOT are, 1) Stage I or II (or with invasive implants), 2) Cystectomy, and 3) Higher pre-operative serum CA125 levels ( $\geq 144 \mathrm{U} / \mathrm{ml})$. Regular surveillance is mandatory if at least two of these risk factors exist (10). Most recurrences are salvageable surgically. Optimal cytoreduction is the treatment of choice. If fertility is still a concern, conservative surgery can be done with the same limitations (non invasive implants, compliance with follow up, awareness of higher incidence of relapse). Residual disease at the completion of secondary debulking is an important prognostic factor as $12 \%$ of patients with optimal debulking died of disease compared with $60 \%$ of patients whose tumour was sub optimally debulked (22). Whether there is any survival benefit from adjuvant chemotherapy, is still controversial.

\section{Reproductive function}

Infertility is frequently observed in patients with BOT and $10-35 \%$ of patients already have a history of infertility before treatment $(24,37,38)$. Several published reports suggest that there is no negative influence of pregnancy on the disease or vice versa $(8,18,24)$. This is evident in our case series also as all those women who conceived had good reproductive outcome.

\section{Safety of fertility drugs?}

A limited number of stimulation cycles and that too in stage-I patients is advised, however points of concern before prescribing fertility drugs are: 1) Identify high risk patients for progression to IOC, 2) Inform patients regarding potential risk, 3) Avoid exposure to long periods of ovulation induction cycles before patients are referred for IVF and embryo transfer, and 4) Monitor women, especially those who failed to conceive, regularly and thoroughly.

\section{Scope of further research}

1. Molecular genetic studies, to clarify whether or not micro papillary serous BOT are in the pathologic continuum to invasive cancer and if recurrent tumors 
are new primaries.

2. Analysis of BOT tumors revealed a high frequency of K-ras mutations and a low frequency of P-53 mutations compared with invasive cancers suggesting distinct origin.

3. Cryopreservation of some healthy ovarian tissue for subsequent fertility treatment, should further recurrences encompass the whole ovarian cortex, seems logical, although the technique is still in its early evolution.

To conclude we can say that BOTs have an overall good prognosis. However maintaining a high index of suspicion, arrangement for frozen section, adequate surgical staging as well as adequate counseling are indispensable. Fertility outcome is favorable. Regular follow up is the key to successful outcome in conservative management.

\section{Ethical issues}

Not applicable.

\section{Conflict of interests}

We declare that we have no conflict of interests.

\section{Acknowledgments}

We have no acknowledgements to disclose.

\section{References}

1. Lalwani N, Shanbhogue AK, Vikram R, Nagar A, Jagirdar J, Prasad SR. Current update on borderline ovarian neoplasms. AJR Am J Roentgenol 2010; 194:330-6.

2. Julian CG, Woodruff JD. The biologic behavior of low grade papillary serous carcinoma of the ovary. Obstet Gynecol 1972; 40:860-7.

3. Leake JF, Currie JL, Rosenshein NB, Woodruff JD. Longterm follow-up of serous ovarian tumors of low malignant potential. Gynecol Oncol 1992;47:150-8.

4. Tavassoli FA, Devilee P. World Health Organization classification of tumors: pathology and genetics of tumors of the breast and female genital organs. Lyon, France: IARC Press; 2003.

5. Gotlieb WH, Chetrit A, Menczer J, Hirsh-Yechezkel G, Lubin F, Friedman E, et al. Demographic and genetic characteristics of patients with borderline ovarian tumors as compared to early stage invasive ovarian cancer. Gynecol Oncol 2005; 97:780-3.

6. Nomelini RS, da Silva TM, Tavares Murta BM, Murta EF. Parameters of blood count and tumor markers in patients with borderline ovarian tumors: a retrospective analysis and relation to staging. ISRN Oncol 2012; 2012:947831.

7. Cadron I, Leunen K, Van Gorp T, Amant F, Neven P, Vergote I. Management of borderline ovarian neoplasms. J Clin Oncol 2007; 25:2928-37.

8. Morice P, Camatte S, El Hassan J, Pautier P, Duvillard P, Castaigne D. Clinical outcomes and fertility after conservative treatment of ovarian borderline tumors. Fertil Steril 2001;75:92-6.

9. Camatte S, Morice P, Thoury A, Fourchotte V, Pautier P, Lhomme C, et al. Impact of surgical staging in patients with macroscopic "stage I" ovarian borderline tumours: analysis of a continuous series of 101 cases. Eur J Cancer $2004 ; 40: 1842-9$
10. Wu TI, Lee CL, Wu MY, Hsueh S, Huang KG, Yeh CJ, et al. Prognostic factors predicting recurrence in borderline ovarian tumors. Gynecol Oncol 2009; 114:237-41.

11. Cadron I, Amant F, Van Gorp T, Neven P, Leunen K, Vergote I. The management of borderline tumours of the ovary. Curr Opin Oncol 2006;18:488-93.

12. Tinelli R, Tinelli A, Tinelli FG, Cicinelli E, Malvasi A. Conservative surgery for borderline ovarian tumors: a review. Gynecol Oncol 2006;100:185-91.

13. Tozzi R, Schneider A. Laparoscopic treatment of early ovarian cancer. Curr Opin Obstet Gynecol 2005; 17:354-8.

14. Ghezzi F, Cromi A, Uccella S, Bergamini V, Tomera S, Franchi $\mathrm{M}$, et al. Laparoscopy versus laparotomy for the surgical management of apparent early stage ovarian cancer. Gynecol Oncol 2007; 105:409-13.

15. Fauvet R, Boccara J, Dufournet C, Poncelet C, Daraï E. Laparoscopic management of borderline ovarian tumors: results of a French multicenter study. Ann Oncol 2005;16:403-10.

16. Romagnolo C, Gadducci A, Sartori E, Zola P, Maggino T. Management of borderline ovarian tumors: results of an Italian multicenter study. Gynecol Oncol 2006; 101:255-60.

17. Donnez J, Munschke A, Berliere M, Pirard C, Jadoul P, Smets M, et al. Safety of conservative management and fertility outcome in women with borderline tumors of the ovary. Fertil Steril 2003; 79:1216-21.

18. Beiner ME, Gotlieb WH, Davidson B, Kopolovic J, Ben-Baruch G. Infertility treatment after conservative management of borderline ovarian tumors. Cancer 2001;92:320-5.

19. Maneo A, Vignali M, Chiari S, Colombo A, Mangioni C, Landoni F. Are borderline tumors of the ovary safely treated by laparoscopy? Gynecol Oncol 2004;94:387-92.

20. Desfeux P, Camatte S, Chatellier G, Blanc B, Querleu D, Lécuru F. Impact of surgical approach on the management of macroscopic early ovarian borderline tumors. Gynecol Oncol 2005; 98:390-5.

21. Zanetta G, Rota S, Chiari S, Bonazzi C, Bratina G, Mangioni C. Behavior of borderline tumors with particular interest to persistence, recurrence, and progression to invasive carcinoma: a prospective study. J Clin Oncol 2001; 19:2658-64.

22. Crispens MA, Bodurka D, Deavers M, Lu K, Silva EG, Gershenson DM. Response and survival in patients with progressive or recurrent serous ovarian tumors of low malignant potential. Obstet Gynecol 2002; 99:3-10.

23. Kehoe S, Powell J. Long-term follow-up of women with borderline ovarian tumors. Int J Gynaecol Obstet 1996; 53:139-43.

24. Gotlieb WH, Flikker S, Davidson B, Korach Y, Kopolovic J, Ben-Baruch G. Borderline tumors of the ovary: fertility treatment, conservative management, and pregnancy outcome. Cancer 1998; 82:141-6.

25. Donnez J, Munschke A, Berliere M, Pirard C, Jadoul P, Smets M, et al. Safety of conservative management and fertility outcome in women with borderline tumors of the ovary. Fertil Steril 2003; 79:1216-21.

26. Salomon LJ, Lhommé C, Pautier P, Duvillard P, Morice P. Safety of simple cystectomy in patients with unilateral mucinous borderline tumors. Fertil Steril 2006; 85:1510.

27. Gershenson DM, Silva EG, Levy L, Burke TW, Wolf JK, Tornos C. Ovarian serous borderline tumors with invasive peritoneal implants. Cancer 1998;82:1096-103. 
28. Chambers JT, Merino MJ, Kohorn EI, Schwartz PE. Borderline ovarian tumors. Am J Obstet Gynecol 1988; 59:1088-94.

29. Camatte S, Morice P, Pautier P, Atallah D, Duvillard P, Castaigne D. Fertility results after conservative treatment of advanced stage serous borderline tumour of the ovary. BJOG 2002; 109:376-380

30. Morice P, Camatte S, Rey A, Atallah D, Lhommé C, Pautier $\mathrm{P}$, et al. Prognostic factors for patients with advanced stage serous borderline tumours of the ovary. Ann Oncol 2003; 14:592-8.

31. Kane A, Uzan C, Rey A, Gouy S, Camatte S, Pautier P, et al. Prognostic factors in patients with ovarian serous low malignant potential (borderline) tumors with peritoneal implants. Oncologist 2009; 14:591-600.

32. Fauvet R, Boccara J, Dufournet C, David-Montefiore E, Poncelet C, Daraï E. Restaging surgery for women with borderline ovarian tumors: results of a French multicenter study. Cancer 2004; 100:1145-51.

33. Lin PS, Gershenson DM, Bevers MW, Lucas KR, Burke TW, Silva EG. The current status of surgical staging of ovarian serous borderline tumors. Cancer 1999; 85:905-911.
34. Silva EG, Gershenson DM, Malpica A, Deavers M. The recurrence and the overall survival rates of ovarian serous borderline neoplasms with noninvasive implants is time dependent. Am J Surg Pathol 2006; 30:1367-71.

35. Silva EG, Tornos C, Zhuang Z, Merino MJ, Gershenson DM. Tumor recurrence in stage I ovarian serous neoplasms of low malignant potential. Int J Gynecol Pathol 1998; 17:16.

36. Zanetta G, Rota S, Lissoni A, Meni A, Brancatelli G, Buda A. Ultrasound, physical examination, and CA 125 measurement for the detection of recurrence after conservative surgery for early borderline ovarian tumors. Gynecol Oncol 2001; 81:63-66.

37. Morris RT, Gershenson DM, Silva EG, Follen M, Morris $\mathrm{M}$, Wharton JT. Outcome and reproductive function after conservative surgery for borderline ovarian tumors. Obstet Gynecol 2000; 95:541-7.

38. Fauvet R, Poncelet C, Boccara J, Descamps P, Fondrinier E, Daraï E. Fertility after conservative treatment for borderline ovarian tumors: a French multicenter study. Fertil Steril 2005; 83:284-90.

Copyright ( 2014 The Author(s); This is an open-access article distributed under the terms of the Creative Commons Attribution License (http://creativecommons.org/licenses/by/4.0), which permits unrestricted use, distribution, and reproduction in any medium, provided the original work is properly cited. 